\title{
Thermoelectric cooling in combination with photovoltaics and thermal energy storage
}

\author{
Jan Skovajsa ${ }^{1, *}$ and Martin Zálešák ${ }^{1}$ \\ ${ }^{1}$ Tomas Bata University in Zlin, Faculty of Applied Informatics, Department of Automation and Control Engineering, Nad Stranemi \\ 4511, Zlin, Czech Republic
}

\begin{abstract}
The article deals with the use of modern technologies that can improve the thermal comfort in buildings. The article describes the usage of thermal energy storage device based on the phase change material (PCM). The technology improves the thermal capacity of the building and it is possible to use it for active heating and cooling. It is designed as a "green technology" so it is able to use renewable energy sources, e.g., photovoltaic panels, solar thermal collectors, and heat pump. Moreover, an interesting possibility is the ability to use thermal energy storage in combination with a photovoltaic system and thermoelectric coolers. In the research, there were made measurements of the different operating modes and the results are presented in the text.
\end{abstract}

\section{Introduction}

The energy consumption of heating, ventilating and air conditioning systems (HVAC) is still increasing with the increasing demand for thermal comfort in the buildings. [1] Nowadays, the energy consumption of the building is decreasing by using the renewable energy sources. Suitable renewable sources for buildings are solar energy, wind energy, geothermal energy and heat pumps. However, these technologies are not able to deal with an insufficient thermal storage capability of the buildings.

Presently, a parameter of sufficient thermal insulation is preferred, which often does not address the thermal storage capability. Mainly buildings constructed from lightweight materials are problematic, where outside heat load variations may cause inappropriate air temperature fluctuations of the inner space. The problem is that the lightweight structures are not able to store a sufficient amount of thermal energy and thus balance the inner environment conditions. Consequently, the user's comfort can be compromised. This problem can be solved by using thermal energy storage. The best way for decreasing the energy consumption and increasing thermal comfort is using of the thermal energy storages means in combination with renewable energy sources e.g. thermal energy storage in combination with a photovoltaic system and thermoelectric coolers.

\subsection{Thermal energy storage}

Thermal energy storage (TES) is temporary holding of thermal energy in the form of hot or cold substances for later utilization. [2] The principle of TES is based on an increase in temperature (sensible TES) or change of phase (latent TES). Starting with an initial solid state, heat addition to the substance first causes sensible heating of the solid, followed by a solid-to-liquid phase change, a sensible heating of the liquid, a liquid-to-vapor phase change and a sensible heating of the vapor. [3]

There are two forms of heat: sensible heat and latent heat. Sensible heat can be defined as a changing of the temperature of the storage substance. The amount of stored heat that caused the temperature growth is commonly called the heat capacity of the storage medium. The main parameter of the accumulation of sensible heat is the specific heat capacity. It determines the amount of energy needed to change the temperature of $1 \mathrm{~kg}$ of the substance by $1 \mathrm{~K}$. The amount of sensible heat energy can be calculated by equation (1).

$$
Q=m \cdot \int_{T_{\mathrm{f}}}^{T_{\mathrm{i}}} c_{p} \mathrm{~d} T
$$

Where

$$
\begin{array}{ll}
m \text { is } & \text { mass }[\mathrm{kg}] \\
T_{\mathrm{i}} & \text { initial temperature }[\mathrm{K}] \\
T_{\mathrm{f}} & \text { final temperature }[\mathrm{K}] \\
c_{\mathrm{p}} & \text { specific heat capacity }\left[\mathrm{J} \cdot \mathrm{kg}^{-1} \mathrm{~K}^{-1}\right]
\end{array}
$$

During the phase change process, the material keeps the temperature constant so called the melting or evaporating temperature as per the case. On the other hand, the heat supplied or released in the process is called latent heat. The quantity of latent heat is derived from the difference in enthalpy of the two relevant cases. Thermal energy storage realized by phase change materials

\footnotetext{
* Corresponding author: jskovajsa@fai.utb.cz
} 
(PCMs) exploits not only sensible, but especially latent heat. [4] That is the reason that PCMs are capable of storing and releasing large amounts of energy. PCMs are either packaged in specialized containers, such as tubes, plane panels and plastic bags, or contained in conventional building elements, such as wall boards and ceilings, or encapsulated as self-contained elements. [5]

Accumulation of latent heat exploits the specific heat capacity and the change of the accumulated medium, during the phase change process where the latent heat is released or absorbed. During the phase change, the temperature of the substance remains constant, and it is possible to store and release large amounts of energy. This is the reason why latent heat storage is one of the most efficient ways of storing thermal energy. [6] The amount of energy is determined by the enthalpy value during the phase change, in the solid state and in the liquid state, according to the following equation (2).

$$
\Delta Q=m \cdot \Delta h
$$

Where $\quad m$ is mass $[\mathrm{kg}]$

$\Delta h \quad$ enthalpy change $\left[\mathrm{J}^{\mathrm{kg}} \mathrm{kg}^{-1}\right]$

Figure 1 below shows the principle of TES in the form of latent and sensible heat in the PCMs.

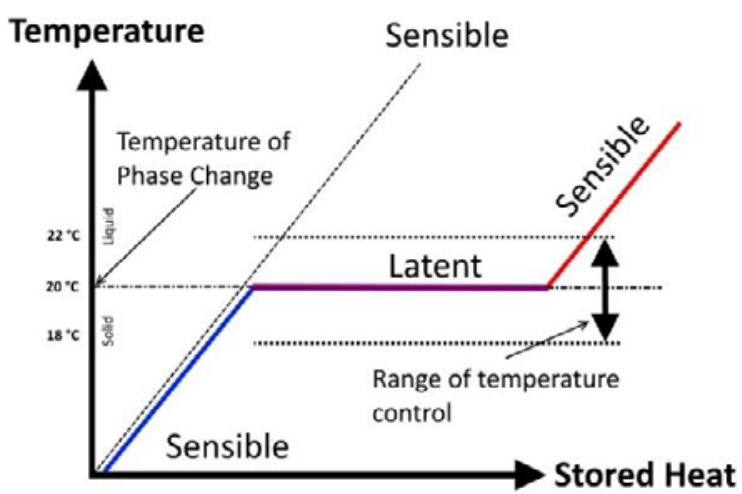

Fig. 1. Sensible heat vs. latent heat and temperature control during the phase change. [7]

\subsection{Phase change material (PCM)}

There are three types of PCM: organic, inorganic and eutectic PCM. The most important property is high thermal energy storage capacity.

Organic PCMs are composed of paraffin, fatty acids or sugar alcohol. The principal advantages are their chemical and thermal stability. They are usually noncorrosive, recyclable and have little or no subcooling. [8] Unfortunately, the disadvantages of using organic PCM are their flammability, low thermal conductivity and lower phase change enthalpy. [9]

Inorganic PCMs include salt hydrates, salts and metals. They cover a wide range of phase change temperatures. The main advantage is higher enthalpy per volume due to their high density. However, they have the disadvantages of corrosion, phase segregation, lack of thermal stability, subcooling and phase separation. [8]
The eutectic PCMs are a combination of chemical compounds or elements that have a single chemical composition and that solidify at a lower temperature than any other composition obtained from the same components. [10]

In fact, all materials can be considered as PCMs. However, effective and predictable energy storage allows only some of them. Figure 2 shows materials suitable for thermal energy storage. For application in buildings, it is necessary to know the specific heat of fusion and the temperature at the time when the phase change occurs. The most commonly used PCMs in buildings are paraffin and salt hydrates. $[11,12]$ The main advantages of the PCMs are reducing of use of cooling systems and using the stored energy during the night.

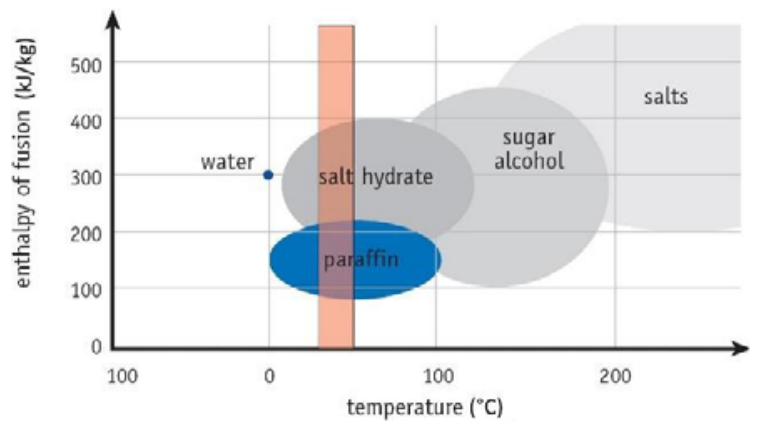

Fig. 2. Classes of materials that can be used as phase change materials and their typical ranges of melting temperatures and melting enthalpies. [13]

PCM can be incorporated in construction materials using different methods. Traditionally, the application in the envelope of the room has been studied as one of the best options because such a solution offers a large area for passive heat transfer. [14]

Efficiency increasing is possible when the PCMs is directly integrated into the energy system in the building. These active systems affect the temperature of the air flow around the element from the PCM. The use of the air flow as forced convection to obtain energy from storage materials is very important. [15] For other applications, PCMs can serve as a reservoir of excess energy for future utilization. One of the possible ways of integrating PCMs into the energy systems is presented in this paper.

\subsection{Thermoelectric cooling system}

Thermoelectric coolers (or Peltier coolers) are solid-state heat pumps. Thermoelectric coolers (TEC) are based on the Peltier effect (Jean Peltier, 1834) to convert electrical energy into a temperature gradient. TECs are composed of a number of n-type and p-type semiconductor junctions. When a DC power source is applied the electrical current flows from the n-type element to the $\mathrm{p}$ type element. The temperature of the cold junction decreases - the electrons pass from a low energy level element (p-type) to a high energy level element (n-type) through the cold junction. At the same time, the electrons carry the absorbed heat to the hot junction. This heat is transferred to the heat sink, whilst the electrons return to 
a lower energy level in the p-type semiconductor (the Peltier effect). [16]

There is a possibility to use thermocouples to generate electrical energy. If there is a temperature difference between the cold and hot junction of n-type and p-type thermoelements, a voltage (Seebeck voltage) directly proportional to the temperature difference is generated. The Peltier effect and the Seebeck effect are shown on the left in Figure 3.
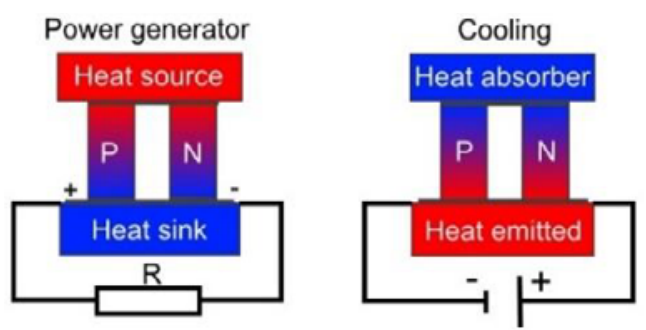

Fig.3. Thermoelectric power generator and cooling device.

Some of the recent studies are focused on TECs and thermoelectric generators (TEGs) define in combination with solar energy and PCMs. TEG is an alternative choice to convert solar energy into electricity from photovoltaic (PV) technology. New areas of research of thermoelectric technology are automotive, cooling of electric devices and buildings, etc. The technology described in this article is able to use electrical energy from PV for cooling the room by TEC in combination with PCM.

\section{Methods}

The proposed technology is based on the paraffin-based PCM grouped into active element. [17] The PCM DuPont Energain uses molecular encapsulation that forms a highly durable PCM with a wide operating temperature range from $0{ }^{\circ} \mathrm{C}$ to $40{ }^{\circ} \mathrm{C}$. The mass of the thermal panels is composed of a mixture of polyethylene and paraffin wax. When the temperature of the panels rises above 18 ${ }^{\circ} \mathrm{C}$, the wax begins to melt and absorbs up to $515 \mathrm{~kJ} \cdot \mathrm{m}^{-2}$ of heat between $18{ }^{\circ} \mathrm{C}$ and $24{ }^{\circ} \mathrm{C}$. It corresponds to standard indoor temperature conditions.

In the following paragraphs are described the basics of the accumulation device and its operation modes, thermocouples and also photovoltaics. More specific information is described in our previous articles, for example dimensions, measurements and improving the heat transfer coefficient, and determined of the time constant. [18-20]

\subsection{Accumulation device}

Measurement of the parameters was done on the technology (see Figure 4 below) which is located in a laboratory at the Faculty of Applied Informatics of Tomas Bata University in Zlin in the Czech Republic. This system is composed of two thermal accumulation panels and each of them is composed of 6 layers of PCM. There are a water tube heat exchanger and three electric heating foils imposed inside the accumulation panels. As previously mentioned, the proposed technology is able to use any common energy sources, including renewable energy sources for heating or cooling, for example heat pumps, solar thermal collectors or It can use photovoltaic systems in combination with electric thermocouples, which is not common in the PCM devices. It is the biggest difference of the technology.

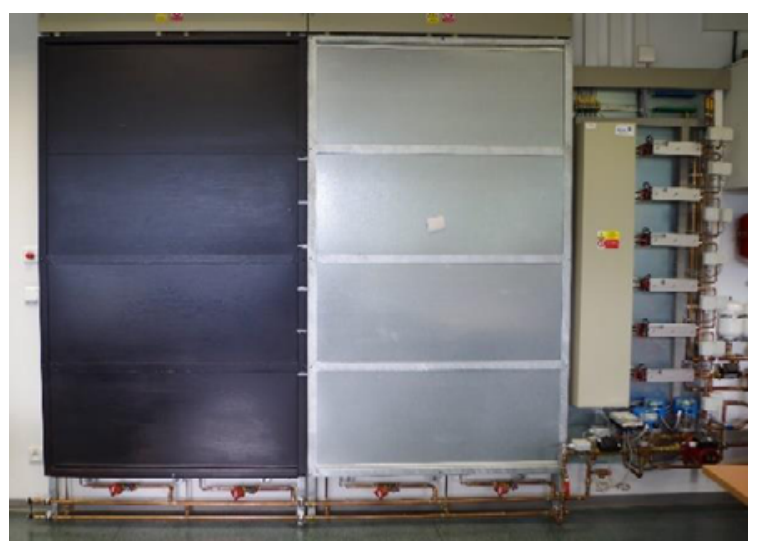

Fig. 4. Thermal panels and thermoelectric assembly on the right.

The whole technology and its connection with the photovoltaic system, monitoring, and controlling system are shown in Figure 5.

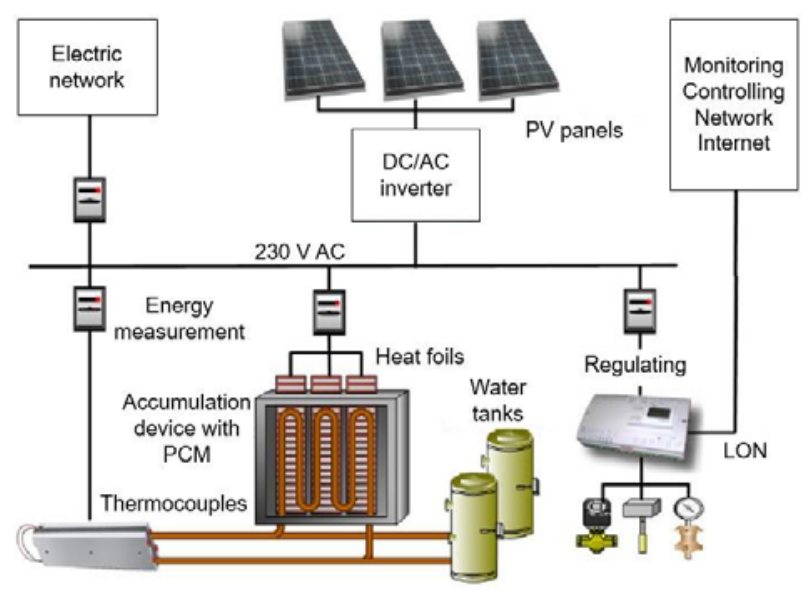

Fig. 5. Components of the technology.

The technology can work in many different modes, which depend on the requirements. The technology can be used as a standard passive system. In this mode, the technology accumulates the heat or cold. This mode can reduce the temperature peaks and keep a stable temperature in the monitored room during the day and night. The technology can also work in active mode. In this mode, the technology is able to influence the room temperature by accumulating the heat or cold obtained from the external sources. Individual operating modes are:

- removing of heat or cold from the thermal panels,

- heating of thermal panels by electric heating foils,

- heating of thermal panels from the hot water tank,

- cooling of thermal panels from the cold water tank,

- cooling of thermal panels by thermoelectric coolers. 


\subsection{Thermoelectric coolers}

The technology includes a thermoelectric coolers powered by the photovoltaic panels or from the power grid. There is used six thermoelectric assembly type L.L.210-24-00-00 in the technology, see Figure 6. The Liquidto-Liquid Series thermoelectric assembly offers dependable, compact performance by cooling objects via liquid to transfer heat. Heat is absorbed through one liquid heat exchanger and dissipated thru a second liquid heat exchanger. The thermoelectric modules are custom designed to achieve a high coefficient of performance (COP) to minimize power consumption. [21]

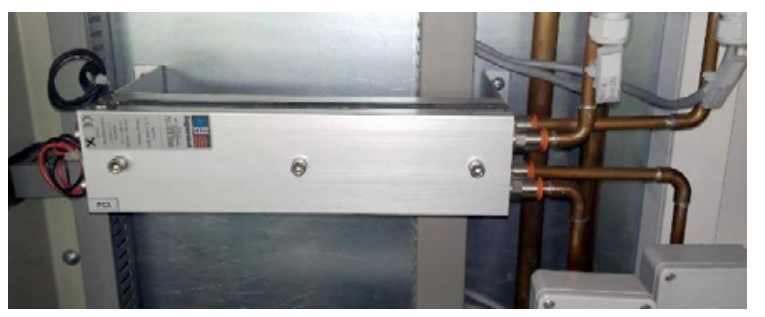

Fig. 6. Thermoelectric assembly type L.L.-210-24-00-00.

Basic specifications of the thermoelectric assembly:

$\begin{array}{llll}\text { - } & \text { Power - Input } & 194 \mathrm{~W} \\ \text { - } & \text { Max. Cooling Power } & 208 \mathrm{~W} \\ \text { - } & \text { Current } & 8.1 & \mathrm{~A} \\ \text { - } & \text { Voltage (DC) } & 24 & \mathrm{~V} \\ \text { - Max. Amb. Temp. } & 62 & { }^{\circ} \mathrm{C}\end{array}$

To determine the number of thermocouples it was necessary to calculate the cooling capacity of the thermal panel. The average specific heat capacity of the thermal panel is about $11 \mathrm{~kJ} \cdot \mathrm{kg}^{-1} \mathrm{~K}^{-1}\left(16\right.$ to $\left.27{ }^{\circ} \mathrm{C}\right)$ and its weight is about $129 \mathrm{~kg}$.

$$
Q=m \cdot \int_{T_{\mathrm{f}}}^{T_{\mathrm{i}}} c_{p} \mathrm{~d} T=15.61 \mathrm{~kJ}=4.34 \mathrm{kWh}
$$

When the charging of the thermal panels takes $8 \mathrm{~h}$, the overall performance of the thermocouples must be about $0.55 \mathrm{~kW}$. For the thermocouples with an efficiency of $50 \%$ there is the input power for the thermocouples required about $1100 \mathrm{~W}$. So, it is necessary to use six thermoelectric assembly type L.L.-210-24-00-00.

\subsection{Photovoltaic system}

For ensuring power supply there is installed the photovoltaic system consists of 9 polycrystalline photovoltaic panels with a total area of $11.25 \mathrm{~m}^{2}$.

In the summer, solar radiation falling on photovoltaic panels has an average intensity of $750 \mathrm{Wm}^{-2}$. Real energy efficiency of the installed photovoltaic system was set at $10.5 \%$. The value was measured in our another research focused on verification of the effectiveness of photovoltaic panels and their economic return. [22, 23] The real power output is a little bit lower than expected consumption of the technology. However, the real power output during the sunny day is higher than maximum power input of the thermoelectric coolers.

\section{Results and discussion}

Measurement of heating of PCMs has already been examined many times. The measurements of heating of the technology are shown in previous articles. [18-20] Thus, the main objective of measured was to find out how's the PCM behave in the temperature range which is specific for cooling. For this purpose, is the specific heat capacity very important parameter. The used PCM has this value around $6800 \mathrm{Jkg}^{-1} \mathrm{~K}^{-1}$ in the temperature range from $10{ }^{\circ} \mathrm{C}$ to $21^{\circ} \mathrm{C}$. The main limiting factor of cooling devices is the risk of condensation of water vapor. Therefore it must be ensured that the surface temperature is at least $1 \mathrm{~K}$ above the dew point.

There are shown in the following text measurements and results of the both passive and active cooling modes. Cooling was made by using the heat pump and thermoelectric cooling.

The first measurement is focused on standard passive mode. In this mode, the accumulation panel is used especially to reduce the temperature fluctuation and also stabilize the indoor air temperature during a few warm days. An example of this behaviour can be seen in Figure 7. This mode ensured to stabilize the indoor air temperature between $23.2{ }^{\circ} \mathrm{C}$ and $24.0{ }^{\circ} \mathrm{C}$ when the outdoor temperature oscillated from $5.3{ }^{\circ} \mathrm{C}$ to $22.7^{\circ} \mathrm{C}$.

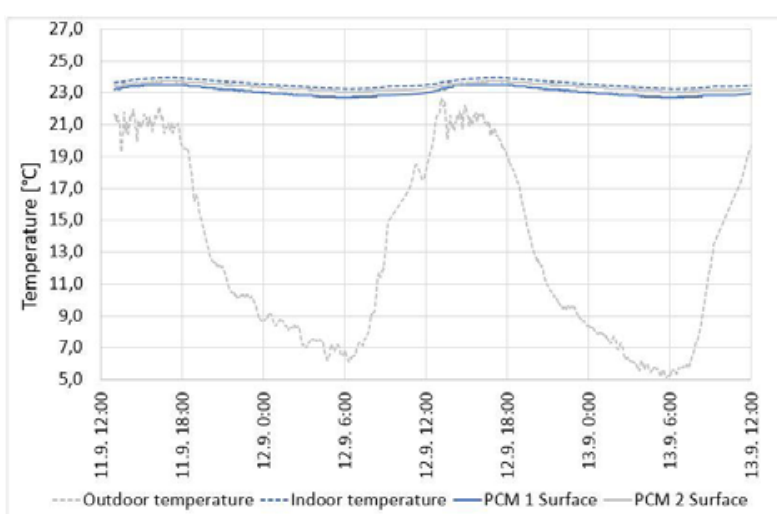

Fig. 7. Passive mode.

The next measurement is focused on the active cooling mode with using of the cooling cycle of the heat pump. Results are shown in Figure 8.

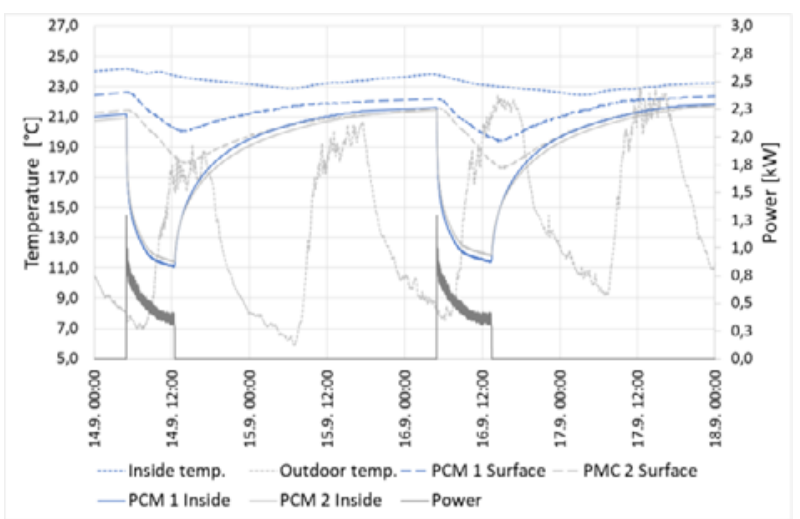

Fig. 8. Active cooling with using of the heat pump. 
In the first cooling cycle, a time of change of the surface temperatures from $21.4^{\circ} \mathrm{C}$ to $17.9^{\circ} \mathrm{C}$ (unmodified surface) and from $22.6{ }^{\circ} \mathrm{C}$ to $20.0{ }^{\circ} \mathrm{C}$ (modified surface) was around $7.5 \mathrm{~h}$. The indoor temperature was decreasing from $24.3{ }^{\circ} \mathrm{C}$ to $23.1{ }^{\circ} \mathrm{C}$ during the day with turned on the active cooling. Then the indoor temperature was still decreasing up to the following morning. The next day the technology was still turned off and the indoor temperature was increasing in accordance with the outdoor temperature.

In the following cooling cycle, the situation and results were very similar to the previous one. The outdoor temperature was higher in this case and the technology was turned on for a longer time. The time of change of the surface temperatures from $21.8{ }^{\circ} \mathrm{C}$ to $17.6^{\circ} \mathrm{C}$ and from $22.4{ }^{\circ} \mathrm{C}$ to $19.3{ }^{\circ} \mathrm{C}$ was around $8.5 \mathrm{~h}$. The indoor temperature was decreasing from $23.8^{\circ} \mathrm{C}$ to $22.6{ }^{\circ} \mathrm{C}$. The process of the re-heating was almost same as in the first cycle. During this cooling cycles, the total amount of energy drained from thermal panels was around $7.9 \mathrm{kWh}$.

The last measured mode is active cooling by thermoelectric coolers powered by the photovoltaic system. As in the previous case, the measurement was done in two cycles during hot days when the outdoor temperature reached up to $25^{\circ} \mathrm{C}$. In this mode, the thermal panels were able to reduce the indoor temperature from $24.0^{\circ} \mathrm{C}$ to $22.9{ }^{\circ} \mathrm{C}$ and from $24.1{ }^{\circ} \mathrm{C}$ to $23.2^{\circ} \mathrm{C}$. Measured parameters are shown in Figure 9.

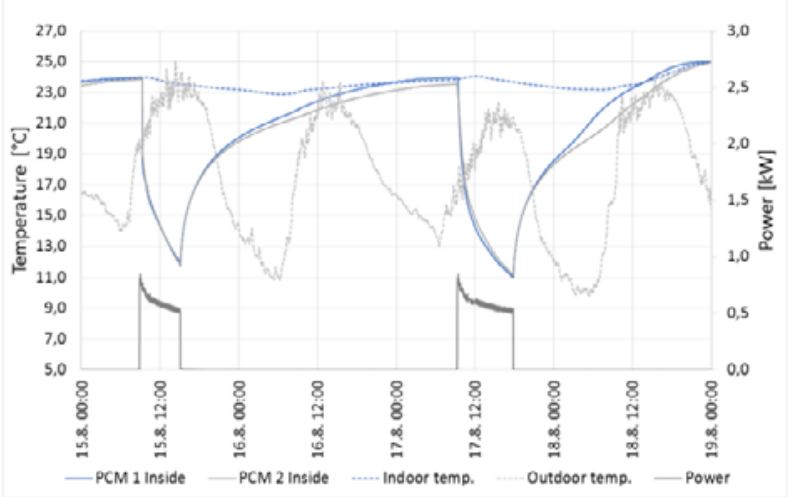

Fig. 9. Active cooling with using with the thermocouples.

In Figure 9, it is possible to see that the first cooling cycle was turned on before at 9 o'clock and it was turned off at 15 o'clock. In the beginning, the indoor temperature was increasing accordance to the outdoor temperature. After turning on the technology, the indoor temperature began to decrease. After turning off, the indoor temperature was steadily decreasing up to the next morning. After that, indoor temperature was increasing again accordance to outdoor temperature.

The following cooling cycle had the similar process. The technology was turned on after 9 o'clock and turned off before 18 o'clock. The indoor temperature decreasing as in the first cycle but then it was increasing fast during the last measured day because the high outdoor temperature and also the temperature of the thermal panel was above the phase change temperature range.
It is possible to judge that area of the thermal panels is low in comparison with the total area of the room. However, it can be resolved by higher heat flux, for example, by forced convection. The thermoelectric coolers were powered by the energy produced by the photovoltaic system. The photovoltaic system produced over $35.5 \mathrm{kWh}$ during the both measured cycles (four days). The heat energy removed from thermal panels was over $8.7 \mathrm{kWh}$. The thermoelectric coolers consumed over $18.5 \mathrm{kWh}$. The energy consumption of the thermoelectric coolers and energy production from renewable energy sources are shown in Figure 10.

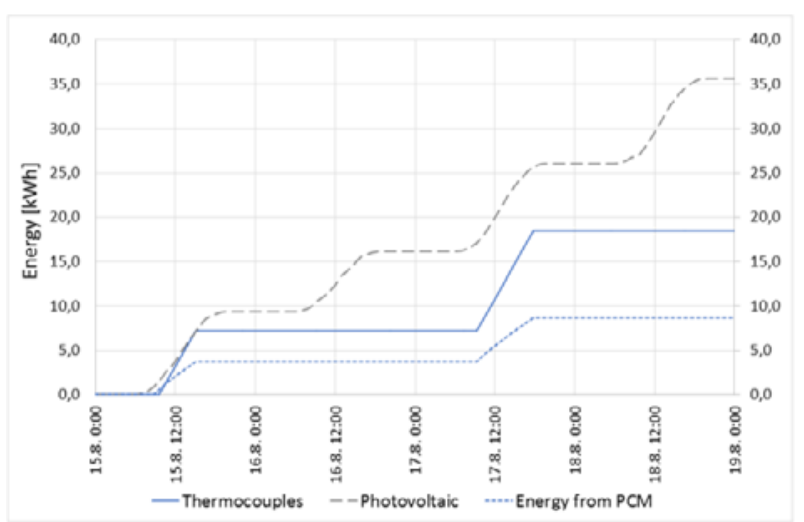

Fig. 10. Energy balance of the thermoelectric cooling.

The disadvantage of the thermoelectric cooling is producing a lot of waste heat on the opposite side of the thermocouples. The hot side of TEC is cooling by a liquid cooler connected to the cold water tank. There is an opportunity to save some energy - use the waste heat for preheating hot water to save energy.

\section{Conclusion}

The proposed PCM-based technology shows possibility of using the PCMs in the active system for heating and cooling. One of the advantages is the possibility to use renewable energy sources and thermoelectric coolers in combination with the photovoltaic system, which is not a common case widely used. The measurement of the proposed technology indicates farther application of the combination of the thermoelectric cooling with the photovoltaic system and other renewable energy sources. Moreover, what might be considered interesting: the utilisation of solar radiation for cooling of the building in the summer. Farther the described system efficiency could be improved by the utilisation of the waste heat from the thermoelectric assembly for preheating of the DHW, water for pool etc.

This work was supported by the Ministry of Education, Youth and Sports of the Czech Republic within the National Sustainability Programme project No. LO1303 (MSMT7778/2014) and also by the European Regional Development Fund under the project CEBIA-Tech No. CZ.1.05/2.1.00/03.0089 and also by the Internal Grant Agency of Tomas Bata University under the project No. IGA/CebiaTech/2017/002 


\section{References}

1. D. Zhou, C.Y. Zhao, Y. Tian, Appl. Energ. 92, 593605 (2012)

2. A.H. Abedin, A.M. Rosen, Open. Renew. Energ. J. 4, 42-46 (2011)

3. K.O. Lee, M.A. Medina, X. Sun, Energ. Buildings, 86, 86-92 (2015)

4. L.G. Socaciu, LEJPT, 75-98 (2012)

5. S.A. Memon, S.A, Renew. Sust. Energ. Rev. 31, 870-906 (2014)

6. M.F. Demirbas, Energ. Source. Part B, 1, 85-95 (2006)

7. H. Mehling, L.F. Cabeza, Heat Mass Transfer, 11-55 (2008)

8. RGEES, An Innovation for Storing Thermal Energy and Temperature Control, (2016)

9. S. Mondal, Appl. Therm. Eng. 1536-1545 (2008)

10. J. Giro-Paloma, M. Martinez, L.F. Cabeza, A.I. Fernandez, Renew. Sust. Energ. Rev. (2016)

11. J. Kosny, Engineering Materials and Processes, 64$81(2015)$

12. A. Castell, I. Martorell, M. Medrano, G. Pérez, L.F. Cabeza, Energ. Buildings, 42, 34-40 (2010)

13. S. Grynning, F. Goia, E. Rognik, B. Time, IJSBE, 2, 56-64 (2013)

14. L. Sánchez, P. Sánchez, A.D. Lucas, M. Carmona, J.F. Rodriguez, Colloid Polym. Sci. 12, 1377-1385 (2007)

15. Energain, DuPontTM Energain RPCM Guidebook, (2010)

16. T.M. Tritt, EMSAT, (2002)

17. T. Habrovansky, Control and monitoring of heating and cooling units in laboratory of building control systems, (2008)

18. M. Kolacek, S. Sehnalek, Heat Mass Transfer, 11, 56-61 (2016)

19. J. Skovajsa, M. Kolacek, M. Zalesak, Energies, 10, 152 (2017)

20. J. Skovajsa, M. Kolacek, M. Zalesak, MATEC Web Conf. 7 (2016)

21. LairdTech, LairdTech website (2017)

22. P. Chrobak, S. Sehnalek, M. Zalesak, Electrorevue, (2014)

23. P. Chrobák, M. Zálešák, M. Opluštil, S. Sehnálek, J. Vincenec, EAD, 10, 320-238 (2014) 